\title{
Mental disorders and termination of education in high-income and low- and middle-income countries: epidemiological study
}

\author{
S. Lee, A. Tsang, J. Breslau, S. Aguilar-Gaxiola, M. Angermeyer, G. Borges, E. Bromet, \\ R. Bruffaerts, G. de Girolamo, J. Fayyad, O. Gureje, J. M. Haro, N. Kawakami, D. Levinson, \\ M. A. Oakley Browne, J. Ormel, J. Posada-Villa, D. R. Williams and R. C. Kessler
}

\section{Background}

Studies of the impact of mental disorders on educational attainment are rare in both high-income and low- and middle-income (LAMI) countries.

\author{
Aims \\ To examine the association between early-onset mental \\ disorder and subsequent termination of education.
}

\section{Method}

Sixteen countries taking part in the World Health Organization World Mental Health Survey Initiative were surveyed with the Composite International Diagnostic Interview ( $n=41688$ ). Survival models were used to estimate associations between DSM-IV mental disorders and subsequent non-attainment of educational milestones.

\section{Results}

In high-income countries, prior substance use disorders were associated with non-completion at all stages of education (OR 1.4-15.2). Anxiety disorders $(\mathrm{OR}=1.3)$, mood disorders
$(\mathrm{OR}=1.4)$ and impulse control disorders $(\mathrm{OR}=2.2)$ were associated with early termination of secondary education. In LAMI countries, impulse control disorders (OR=1.3) and substance use disorders $(\mathrm{OR}=1.5)$ were associated with early termination of secondary education.

\section{Conclusions}

Onset of mental disorder and subsequent non-completion of education are consistently associated in both high-income and LAMI countries.

\section{Declaration of interest}

R.C.K. has been a consultant for GlaxoSmithKline, Kaiser Permanente, Pfizer Inc, Sanofi-Aventis, Shire Pharmaceuticals and Wyeth-Ayerst; has served on advisory boards for Eli Lilly \& Company and Wyeth-Ayerst; and has had research support for his epidemiological studies from Bristol-Myers Squibb, Eli Lilly \& Company, GlaxosmithKline, Johnson \& Johnson Pharmaceuticals, Ortho-McNeil Pharmaceutical Inc, Pfizer Inc and Sanofi-Aventis.
Studies of mental disorders may underestimate the long-term adverse consequences of such disorders owing to a dominant focus on disability contemporaneous with the acute phases of disease. Of particular concern is the impact of mental disorders on educational attainment, an important determinant of adult life chances in both high-income and low- and middle-income countries. ${ }^{1}$ Early-onset mental disorders (LAMI) - i.e. those beginning in childhood or adolescence - may increase the risk of early termination of education. ${ }^{2-5}$ The latter has been shown to have adverse life-course consequences on individuals, such as poor health, as well as societal consequences, such as greater demand on social welfare entitlements. Early termination of education also affects the standard of living, social mobility and upbringing of citizenship. Because of these connections between mental disorders and educational attainment, mental health should be a focus of concern in the discussion of policy on education and workforce development. To date, studies of mental disorders and subsequent educational attainment have been limited to the USA and New Zealand. These studies found significant associations between mental disorders and subsequent early termination of education at all levels from primary through tertiary education, with stronger associations for substance use disorders and disorders of impulse control, such as attentiondeficit hyperactivity disorder (ADHD) or conduct disorder, than for anxiety or mood disorders, such as generalised anxiety disorder or major depression..$^{2-6}$ None the less, it is unclear whether these preliminary findings are similar across a broader range of high-income countries or in countries where national healthcare and educational institutions are less developed.

\section{Method}

This study was part of the World Mental Health (WMH) Survey Initiative, a project of the World Health Organization (WHO) that aims to obtain accurate cross-national information about the prevalence, risk factors, impairment, pattern of treatment and societal cost of mental disorders in both high-income and LAMI countries (www.hcp.med.harvard.edu/wmh/). Recent WMH studies on the social consequences of mental disorders have demonstrated that mental disorders have more adverse effects on role functioning than most physical diseases, ${ }^{7}$ and that untreated mental disorders have substantial adverse effect on the number of out-of-role days and work functioning. ${ }^{8}$ Our study examines the association between mental disorders and termination of education, which is another important indicator of human capital development.

\section{Sample}

Using the WMH Survey Initiative version of the WHO Composite International Diagnostic Interview (CIDI, version 3.0), ${ }^{9} 16$ crosssectional surveys were carried out in seven countries classified as LAMI - China (Beijing and Shanghai), Colombia, Lebanon, Mexico, Nigeria, South Africa and Ukraine - and nine countries classified as high-income - Belgium, Germany, Israel, Italy, Japan, The Netherlands, New Zealand, Spain and the USA (online Table DS1). The assignment of country developmental status was based on a cut-off of 0.9 on the Human Development Index. ${ }^{10}$ 
All surveys were based on either multistage, clustered area probability household samples or individuals randomly selected from national registers. All interviews were carried out face to face by trained lay interviewers. The western European surveys were carried out jointly. ${ }^{11}$ The weighted average response rate was $70.8 \%$.

Internal subsampling was used to reduce respondent burden by dividing the interview schedule into two parts. Part 1 included the core diagnostic assessment of mental disorders. Part 2 consisted of a detailed risk-factor questionnaire (including years of education and indicators of childhood and family adversity) and a series of diagnoses of secondary interest. All respondents completed part $1 \quad(n=113216)$. Respondents who met criteria for any mental disorder, as well as a probability sample of those who did not, were administered part 2 of the interview, except in Israel and South Africa where all respondents completed both parts. Data for part 2 respondents were weighted by the inverse of their probability of selection for part 2 of the interview to adjust for differential sampling. Analyses in this article were based on the weighted part 2 subsample $(n=41688)$. Additional weights were used to adjust for differential probabilities of selection within households and to match the samples to population sociodemographic distributions.

\section{Measures}

The WMH CIDI is a fully structured diagnostic interview for assessing mental disorders and collecting detailed information about the risk factors, impairment, consequences and treatment. ${ }^{9}$

\section{Mental disorder status}

Four categories of mental disorders were considered: anxiety disorders (generalised anxiety disorder, specific phobia, panic disorder and/or agoraphobia, post-traumatic stress disorder, separation anxiety disorder and social phobia); mood disorders (major depressive disorder, dysthymia and bipolar disorder); behaviour/impulse control disorders (intermittent explosive disorder, conduct disorder, oppositional defiant disorder and ADHD); and substance use disorders (alcohol and drug abuse and dependence). Disorders were assessed using the definitions and criteria of DSM-IV. ${ }^{12}$ The CIDI organic exclusion rules were imposed in making all diagnoses. For each disorder retrospective age-at-onset reports, on both important symptoms and full syndromes, were obtained using a specially designed series of questions to minimise response bias. Such data were important in analysing the association between onset of prior mental disorders and subsequent termination of education.

\section{Educational attainment}

Respondents were asked how many years of education they had completed. Although countries varied in the age of starting school and the duration of each stage of education, we standardised the stage of education within country by years of education. We assumed an orderly academic progression and defined four educational milestones as follows: finishing primary education, finishing secondary education, entry to tertiary education and graduation from tertiary education (including university or other higher levels of education after secondary education). The standardisation of these educational stages across countries was performed with information supplied by researchers from all participating countries. Data on childhood adversities, collected through questionnaires on risk factors included in the survey instrument, were included as covariates because of their known association with both educational attainment and risk of mental disorders. ${ }^{13,14}$ These adversities included three forms of child maltreatment (physical abuse, sexual abuse, neglect), three forms of loss of parents (parental death, parental divorce, other parental loss), three forms of parental psychopathology (parental mental disorder, parental substance use, antisocial personality disorders), family violence, family economic adversity and severe childhood physical illness (further information about the questionnaire is given in online Table DS2). Respondents who met the criteria specified for a given adversity before the age of 18 years were coded as having experienced childhood family adversity. We then estimated the risk of early termination of education attributable to mental disorders, controlling for childhood adversities, within each of the 16 countries studied.

\section{Training and field procedures}

The WHO translation protocol was used to translate instruments and training materials. Experienced CIDI trainers in the USA trained bilingual supervisors in each country. The surveys were conducted in the local official languages of the survey sites by trained lay interviewers. Two surveys were carried out in bilingual form (Dutch and French in Belgium; Russian and Ukrainian in Ukraine). In Nigeria, interviews were conducted in the four languages (Yoruba, Hausa, Igbo and Efik) used in the respective regions where the survey was carried out. Consistent interviewer training documents and procedures were used across surveys. People who could not speak the survey languages were excluded. Standardised descriptions of the goals and procedures of data use and its protection, and the rights of respondents were provided in both written and verbal forms to all potentially eligible respondents before their verbal informed consent to participate was obtained. Quality control protocols, described in detail elsewhere, ${ }^{15}$ were standardised across countries to check on interviewer accuracy and to specify data cleaning and coding procedures. The institutional review board of the organisation that coordinated the survey in each country approved and monitored compliance with procedures for obtaining informed consent and protecting participants.

\section{Statistical analysis}

Data on the age at onset of each disorder were combined with information on educational attainment to fit a discrete-time survival model in which disorders were treated as time-varying predictors of early termination of schooling. ${ }^{16}$ Each year of education was treated as a separate observational record with a dichotomous outcome variable, ${ }^{17,18}$ i.e. whether the respondent prematurely terminated (coded 1) or completed (coded 0) schooling in that year. The resulting data array consisted of 494063 person-year observations (equivalent to a median of 12 years of education for each of the 41688 respondents).

Models of the association between mental disorders and subsequent early termination of education included respondents' childhood family adversities, statistical controls for birth cohort (age at the time of interview), dummy variables for countries, and sociodemographic variables related to both educational attainment ${ }^{19-21}$ and mental disorders. ${ }^{22}$ These included measures of family of origin, socioeconomic status (standardised years of education of parents), respondents' and their families' place of birth (i.e. whether respondents were born in their country of residence, whether their parents/grandparents wre born in their country of residence). Individual country-level models differed from one another owing to differences in the covariate information collected in the surveys. Respondents' place of birth was not included in surveys in Beijing, Shanghai, Colombia, Lebanon, Mexico, Nigeria and South Africa. Parental neglect, death and divorce were not included in the models for Europe 
and New Zealand. To accommodate these differences in covariate information across the surveys, the number of childhood family adversities for each person-year was summed and standardised by person-year within each country. We then compared countries by including these individual measures and their interactions with country.

To estimate the societal-level associations of mental disorders with educational attainment, we used logistic regression equations to predict termination prior to each of the educational milestones from predictors including all the control variables listed above and binary indicators for individual mental disorders. On the basis of these equations we calculated the population attributable risk proportion using the difference between average predicted probability of completing the milestone with and without mental disorders.

Separate models were estimated for each of the 17 disorders and 4 disorder categories described earlier. In addition, we estimated models for any mental disorder and for composite disorders (no disorder $v$. exactly one disorder, exactly two disorders, or three or more disorders). The relationships between mental disorders and subsequent non-completion of each educational milestone are presented as odds ratios. Odds ratios greater (or less) than 1.0 are associated with greater (or lower) chances of educational non-completion. With sociodemographic variables controlled, an odds ratio of 2.0 can be interpreted as showing that the odds of early educational termination among people with a particular prior disorder were twice the odds of termination among others. Confidence intervals and statistical tests were calculated using the Taylor series linearisation method as implemented in the SUDAAN software package (Software for Survey Data Analysis, version 8.1 on UNIX-Solario/SUN OS) to account for the complex sample design. Significance was assessed using two-sided tests at the 0.05 probability level.

\section{Results}

\section{Prevalence of educational non-completion}

The sample included 41688 individuals: 26109 in high-income countries and 15579 in LAMI countries (online Table DS1). In the high-income countries a small minority (6\%) did not complete primary education; of those who did so, $24.7 \%$ did not complete secondary education; $49.3 \%$ of those who completed secondary school did not enter tertiary education; and $46.2 \%$ of those who entered tertiary education left before completing 4 years at that level.

Termination of education typically occurred earlier in the LAMI countries than in the high-income countries: $16.6 \%$ of the former sample did not complete primary education; $46.1 \%$ of those who completed primary education left school before completing their secondary education; $40.1 \%$ of those who completed secondary education did not enter tertiary education; and $55.1 \%$ of those who entered tertiary education did not complete it (Table 1). In each sample, a small number of respondents (289 in the high-income country sample and 342 in the LAMI country sample) were still in secondary or tertiary education when they were interviewed.

\section{Association between mental disorder and early termination}

In the total sample of all surveyed sites, respondents with one or more prior mental disorders of any type were significantly likely to terminate secondary education $\left(\mathrm{OR}=1.2-1.3\right.$, Wald $\chi^{2}=38.5$, $P<0.01)$ and tertiary education $\left(\mathrm{OR}=1.0-1.2\right.$, Wald $\chi^{2}=5.7$, $P=0.02)$ before completion. Different patterns of association were found between high-income and LAMI countries on the association between mental disorders and early termination of education. For instance, respondents having more disorders were significantly associated with higher odds of early termination than those having one disorder in high-income countries, but not in LAMI countries. To take account of this variation we conducted subsequent analyses separately for high-income and LAMI countries.

\section{High-income countries}

Of the 68 associations between individual mental disorders and subsequent termination of education in the high-income countries examined, 40 associations showed statistically significant odds ratios greater than 1.0. Table 2 shows the associations of the four mental disorder categories; complete results are shown in online Table DS3. For primary education, substance use disorders showed a significant and strong association with early termination at this stage (ORs 8.1-19.0), partly because of the small number of respondents with such disorders. There were a few significant associations between termination at this stage and disorders such as post-traumatic stress disorder $(\mathrm{OR}=3.8,95 \%$ CI 1.4-10.3), dysthymia $(\mathrm{OR}=2.9,95 \% \mathrm{CI} 1.1-7.6)$ and oppositional defiant disorder $(\mathrm{OR}=2.9,95 \%$ CI 1.1-7.7).

Every disorder examined was significantly associated with termination prior to completion of secondary education among those who completed primary education. However, the significant associations with termination were less substantial for anxiety (ORs 1.2-1.6) and mood disorders (ORs 1.4-1.7) than for impulse control (ORs 2.0-3.6) and substance use disorders (ORs 2.4-3.9). Drug abuse $(\mathrm{OR}=3.5,95 \% \mathrm{CI} 2.8-4.4)$ and dependence $(\mathrm{OR}=3.9$, 95\% CI 2.6-5.8) and conduct disorders ( $\mathrm{OR}=3.6,95 \% \mathrm{CI} 2.5-4.9)$

\begin{tabular}{|c|c|c|c|c|c|}
\hline Educational milestone & At risk, $n$ & $\begin{array}{l}\text { Terminated prior to } \\
\text { completion, } n\end{array}$ & Censored, $^{a} n$ & $\begin{array}{l}\text { Proportion terminated } \\
\text { among those at risk } \\
\% \text { (s.e.) }\end{array}$ & $\begin{array}{c}\text { Proportion terminated } \\
\text { among total part } 2 \text { sample } \\
\% \text { (s.e.) }\end{array}$ \\
\hline \multicolumn{6}{|l|}{ High-income countries } \\
\hline Primary school & 26109 & 1761 & 0 & $6.0(0.2)$ & $6.0(0.2)$ \\
\hline Secondary school & 24348 & 6867 & 2 & $24.7(0.4)$ & $23.3(0.3)$ \\
\hline Entry to tertiary education & 17479 & 7744 & 130 & $49.3(0.5)$ & $34.9(0.4)$ \\
\hline Tertiary education & 9605 & 4619 & 157 & $46.2(0.7)$ & $16.3(0.3)$ \\
\hline \multicolumn{6}{|l|}{ LAMI countries } \\
\hline Primary school & 15579 & 2974 & 0 & $16.6(0.4)$ & $16.6(0.4)$ \\
\hline Secondary school & 12605 & 6186 & 40 & $46.1(0.6)$ & $38.4(0.5)$ \\
\hline Entry to tertiary education & 6379 & 2660 & 141 & $40.1(0.8)$ & $17.9(0.4)$ \\
\hline Tertiary education & 3578 & 2038 & 161 & $55.1(1.1)$ & $14.1(0.4)$ \\
\hline
\end{tabular}




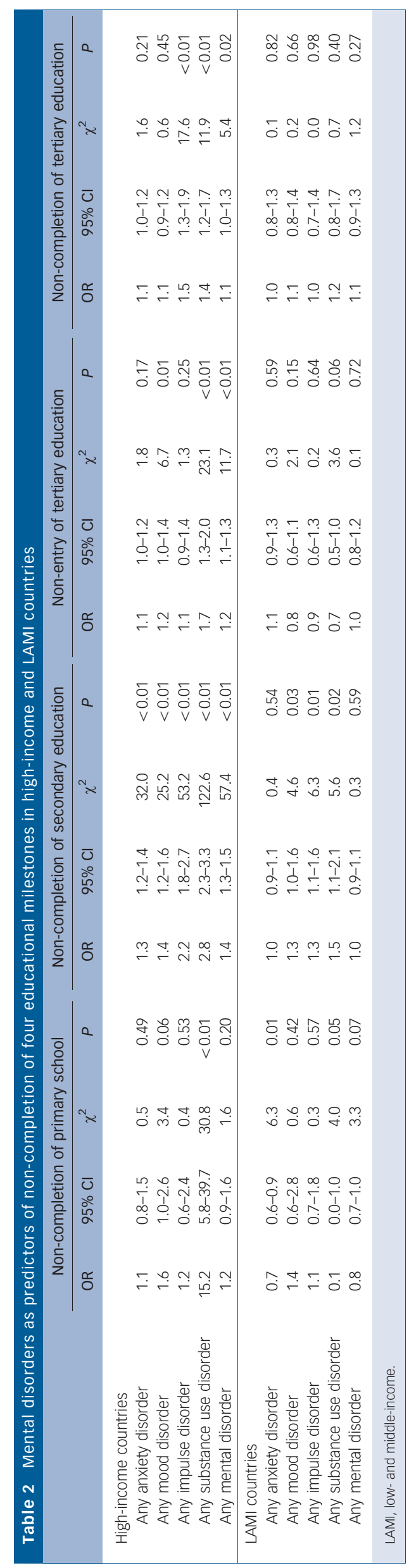

were the most strongly associated disorders. Among those who completed secondary education, not entering tertiary education was significantly associated with panic disorder/agoraphobia $(\mathrm{OR}=1.4,95 \% \mathrm{CI} 1.1-1.7)$, separation anxiety disorder $(\mathrm{OR}=1.5$, 95\% CI 1.1-2.0), bipolar disorder ( $\mathrm{OR}=1.5,95 \%$ CI 1.1-2.0), oppositional defiant disorder $(\mathrm{OR}=1.5,95 \%$ CI 1.1-2.0) and ADHD (OR=1.4, 95\% CI 1.0-1.8), and all four substance use disorders (ORs 1.4-1.9).

Impulse control (ORs 1.4-2.0) and substance use (ORs 1.41.5) disorders were most strongly associated with non-completion of tertiary education among those gaining entry to university. Such termination was only inconsistently associated with panic disorder/agoraphobia ( $\mathrm{OR}=1.4,95 \% \mathrm{CI} 1.1-1.8)$ and with bipolar disorder at trend level $(\mathrm{OR}=1.3,95 \% \mathrm{CI} 1.0-1.8, P=0.07)$. At all four educational milestones greater complexity of mental health condition, as indicated by a higher number of comorbid disorders, was associated with increasing odds of early termination.

\section{Low- and middle-income countries}

Of the 64 associations estimated between individual mental disorders and subsequent termination of education, 29 odds ratios exceeded 1.0 and 6 of these reached statistical significance. Twenty-eight associations showed odds ratios of less than 1 and three of these reached statistical significance (online Table DS4). During primary education, social phobia $(\mathrm{OR}=0.4,95 \%$ CI $0.2-$ $0.9)$ and separation anxiety disorder $(\mathrm{OR}=0.5,95 \%$ CI $0.3-1.0)$ were significantly associated with lower odds of termination of education. Among those who entered secondary education, generalised anxiety disorder was significantly associated with lower odds of termination $(\mathrm{OR}=0.6,95 \%$ CI $0.3-1.0)$, whereas bipolar disorder $(\mathrm{OR}=1.8,95 \% \mathrm{CI} 1.1-3.0)$, conduct disorder (OR=3.0, 95\% CI 2.0-4.4), oppositional defiant disorder $(\mathrm{OR}=1.6,95 \%$ CI 1.1-2.2), alcohol abuse (OR=1.6, 95\% CI 1.02.5) and drug dependence $(\mathrm{OR}=3.2,95 \%$ CI 1.2-8.3) were associated with higher odds of termination. Among those who completed secondary education, only oppositional defiant disorder was significantly associated with higher odds of non-entry to tertiary education ( $\mathrm{OR}=2.1,95 \% \mathrm{CI}$ 1.1-4.2). Among those who entered tertiary education, no disorder was significantly associated with non-completion of education. In contrast to high-income countries, in LAMI countries a larger number of disorders per respondent was associated with lower odds of early termination in primary education and higher odds of early termination in secondary education.

\section{Population attributable risk}

These simulations generated the expected risks of early termination of education of the population in the presence or absence of any prior mental disorders (Table 3). Comparison of these estimates showed the change in probability of not completing a particular stage of education attributable to all mental disorders. For example, in the USA the probability of people not completing secondary education increased by $11.4 \%$ in the presence of any mental disorder. The overall pattern showed that the percentage change of people not attaining educational milestones attributable to prior mental disorders was generally larger in high-income countries than in LAMI countries. Among all educational milestones, the change of probability between those with mental disorder and those without was largest for the stage of completing secondary education in both high-income and LAMI countries. 


\begin{tabular}{|c|c|c|c|c|c|c|c|c|c|c|c|c|}
\hline \multirow[b]{2}{*}{ Country } & \multicolumn{3}{|c|}{$\begin{array}{l}\text { Did not complete } \\
\text { primary school }\end{array}$} & \multicolumn{3}{|c|}{$\begin{array}{c}\text { Did not complete } \\
\text { secondary education }\end{array}$} & \multicolumn{3}{|c|}{$\begin{array}{l}\text { Did not enter } \\
\text { tertiary education }\end{array}$} & \multicolumn{3}{|c|}{$\begin{array}{l}\text { Did not complete } \\
\text { tertiary education }\end{array}$} \\
\hline & $\begin{array}{l}\text { Without } \\
\text { disorder }\end{array}$ & $\begin{array}{c}\text { With } \\
\text { disorder }\end{array}$ & $\begin{array}{c}\text { Change } \\
\%\end{array}$ & $\begin{array}{l}\text { Without } \\
\text { disorder }\end{array}$ & $\begin{array}{c}\text { With } \\
\text { disorder }\end{array}$ & $\begin{array}{c}\text { Change } \\
\%\end{array}$ & $\begin{array}{l}\text { Without } \\
\text { disorder }\end{array}$ & $\begin{array}{l}\text { With } \\
\text { disorder }\end{array}$ & $\begin{array}{c}\text { Change } \\
\%\end{array}$ & $\begin{array}{l}\text { Without } \\
\text { disorder }\end{array}$ & $\begin{array}{c}\text { With } \\
\text { disorder }\end{array}$ & $\begin{array}{c}\text { Change } \\
\%\end{array}$ \\
\hline \multicolumn{13}{|l|}{ High-income countries } \\
\hline Belgium & 0.0597 & 0.0597 & 0 & 0.2973 & 0.3015 & 1.41 & 0.5181 & 0.5361 & 3.47 & 0.7531 & 0.7641 & 1.46 \\
\hline Germany & 0.0049 & 0.0053 & 8.16 & 0.3660 & 0.3662 & 0.05 & 0.5816 & 0.5826 & 0.17 & 0.9649 & 0.9649 & 0 \\
\hline Israel & 0.0069 & 0.0069 & 0 & 0.2596 & 0.2611 & 0.58 & 0.5420 & 0.5427 & 0.13 & 0.7533 & 0.7537 & 0.05 \\
\hline Italy & 0.2954 & 0.2960 & 0.20 & 0.6133 & 0.6147 & 0.23 & 0.8096 & 0.8092 & -0.05 & 0.8750 & 0.8767 & 0.19 \\
\hline Japan & 0.0125 & 0.0125 & 0 & 0.2961 & 0.2961 & 0 & 0.6227 & 0.6227 & 0 & 0.8070 & 0.8107 & 0.46 \\
\hline The Netherlands & 0.0518 & 0.0518 & 0 & 0.3013 & 0.3097 & 2.79 & 0.4110 & 0.4195 & 2.07 & 0.6530 & 0.6618 & 1.35 \\
\hline New Zealand & 0.0084 & 0.0090 & 7.14 & 0.3836 & 0.4026 & 4.95 & 0.6476 & 0.6753 & 4.28 & 0.7946 & 0.8147 & 2.53 \\
\hline Spain & 0.2654 & 0.2663 & 0.34 & 0.5870 & 0.5901 & 0.53 & 0.6401 & 0.6427 & 0.41 & 0.7998 & 0.8079 & 1.01 \\
\hline USA & 0.0275 & 0.0286 & 4 & 0.1521 & 0.1694 & 11.37 & 0.4687 & 0.4905 & 4.65 & 0.7417 & 0.7613 & 2.64 \\
\hline \multicolumn{13}{|l|}{ LAMI countries } \\
\hline Colombia & 0.1674 & 0.1674 & 0 & 0.5367 & 0.5436 & 1.29 & 0.7488 & 0.7519 & 0.41 & 0.8889 & 0.8903 & 0.16 \\
\hline Lebanon & 0.2523 & 0.2541 & 0.71 & 0.6008 & 0.6077 & 1.15 & 0.7172 & 0.7220 & 0.67 & 0.8108 & 0.8136 & 0.35 \\
\hline Mexico & 0.1749 & 0.1754 & 0.29 & 0.6959 & 0.6996 & 0.53 & 0.8136 & 0.8157 & 0.26 & 0.8661 & 0.8692 & 0.36 \\
\hline Nigeria & 0.2188 & 0.2188 & 0 & 0.6476 & 0.6477 & 0.02 & 0.8183 & 0.8184 & 0.01 & 0.9234 & 0.9246 & 0.13 \\
\hline $\begin{array}{l}\text { China (Beijing } \\
\text { \& Shanghai) }\end{array}$ & 0.0684 & 0.0684 & 0 & 0.4577 & 0.4577 & 0 & 0.6960 & 0.6960 & 0 & 0.9696 & 0.9698 & 0.02 \\
\hline South Africa & 0.1978 & 0.1978 & 0 & 0.6187 & 0.6194 & 0.11 & 0.8454 & 0.8472 & 0.22 & 0.9670 & 0.9682 & 0.12 \\
\hline Ukraine & 0.0638 & 0.0638 & 0 & 0.1789 & 0.1844 & 3.07 & 0.3208 & 0.3277 & 2.15 & 0.6421 & 0.6454 & 0.51 \\
\hline
\end{tabular}

\section{Discussion}

\section{Limitations}

The results of this study should be interpreted in light of several limitations. We did not collect individual-specific information on school levels that a respondent had to repeat, or interruptions in schooling including return to school after a hiatus. Lack of a more detailed chronology of respondents' educational careers might have led our analysis to underestimate the association between disorders and termination of education. Moreover, national requirements for completing basic education and the implementation of such requirements vary across countries. The assumption that all respondents completed basic education in accordance with governmental requirements, whether they had mental disorders or not, may be an oversimplification.

Our assumption of an orderly academic progression may classify some disorders as having onset subsequent to educational termination even though the disorder might have actually occurred prior to termination. This is because disorder onset and termination of education were assessed by age and years of completed education respectively. Our analysis may also underestimate the impact of mental disorders on educational attainment because we did not examine other forms of educational termination that mental disorders can bring about. For example, mental disorders may influence grade-point averages among graduates, an outcome known to have important implications for accomplishments in later life. ${ }^{23}$ Given that health-related behaviours in adolescence may influence the process of selection into educational tracks and hence social position in adulthood, ${ }^{24}$ individuals with mental disorders may also select less competitive fields of study that minimise chance of access to a higher level of regular education. It therefore needs emphasising that termination of education is the end-point of a potentially complex process that may have its onset many months or years before the date of leaving education. The cross-sectional nature of our surveys clearly limits the interpretation of causal relationship between prior mental disorder and subsequent termination of education. Moreover, the WMH Survey sample may contain a lower proportion of respondents with a history of mental disorders than the general population because of its incomplete sampling frame (e.g. exclusion of homeless individuals) and the likelihood that non-respondents had higher rates of disorders than respondents. ${ }^{25}$ Our results hinged on respondents' recall of age at onset of particular disorders. We attempted to be conservative in this regard by asking the respondents to judge their certainty in recalling age at onset and, in cases of uncertainty, using the earliest age at which a respondent could remember a particular episode of the disorder (an upper bound on age at onset) as the age at onset in our analysis. Despite the use of a fully structured diagnostic instrument and rigorously trained lay interviewers, the validity of psychiatric diagnoses may vary across countries because of methodological factors such as problems in translation of research instruments, stigma-induced concealment and somatisation. ${ }^{26}$ This may give rise to artificially large cross-national variations in the prevalence of mental disorders. ${ }^{27,28}$ In addition to the above limitations, it is worth noting that because termination of education may trigger mental disorders in susceptible individuals, our assumption of an association between antecedent mental disorders and subsequent educational termination may err in the direction of excluding some disorders that could result partly from the termination itself. ${ }^{29,30}$ Future studies should therefore examine the extent to which school performance explains the association between mental disorders and educational termination.

\section{Comparison with previous studies}

With the above caveats, this is the first study to examine associations between mental disorders and subsequent educational termination using data from a much broader range of highincome and LAMI countries than has previously been studied. The findings are consistent with previous population-based studies in the USA and New Zealand with respect to three general patterns. ${ }^{2-5}$ First, mental disorders were shown to be commonly associated with higher odds of early termination of education. In the high-income countries, associations of mental disorders with early termination of education were more consistently 
significant than in previous studies, possibly owing to the large sample size in this study. Second, among mental disorders, impulse control and substance use disorders were more consistently associated with early termination of education than mood or anxiety disorders. This pattern, which has been found in several prior studies, ${ }^{4,31}$ occurred in both high-income and LAMI country samples in this study. Third, among the educational milestones we examined, the strongest and most consistent associations with mental disorders were for termination prior to completion of secondary education.

\section{Explanations for the association}

Substance use disorders were more extensively associated with non-completion of the various stages of education than all other mental disorders, especially in high-income countries. Generally, associations between mental disorders and subsequent termination of education were weaker and less consistent in LAMI than in high-income countries. For example, substance use disorders were associated only with termination in primary and secondary education in LAMI countries but with all stages of education termination in high-income countries. For several anxiety disorders (social phobia, generalised anxiety disorder and separation anxiety disorder) there were significant negative associations with early termination in the LAMI countries, indicating that in these countries people with these disorders are more likely to complete their education. These counterintuitive findings may result from random variations, given the large number of associations we have examined. None the less, there may be other explanations for these associations that should be examined in future studies. For example, anxiety disorders might be associated with psychological qualities that are conducive to positive educational outcome in these populations: for instance, individuals with anxiety disorders might over-prepare because of excessive anticipatory worries of failure and might be more responsive to high familial expectations of obtaining good school grades. They may also remain in school, because common anxietyrelated manifestations, such as shyness and over-preparation, may be culturally tolerated in the examination-oriented education system of LAMI countries. ${ }^{32}$ The relatively high proportion of the population that did not complete their education and the lower relative risks of early educational termination associated with mental disorders in the LAMI country sample suggest that ultimate educational attainment in these countries may be associated with family, community and other factors that operate independently of mental health. ${ }^{1}$ Further country-specific analysis and in-depth contextual studies are needed to examine the considerable variation that remains among countries in the change of probability of not completing a particular stage of education attributable to mental disorders.

\section{Implications}

Published studies on the social cost of mental disorders have focused on depression-related disability in the workplace. ${ }^{33}$ They do not capture the cost of educational termination long before the large number of individuals with early-onset mental disorders enter the workforce. Research has shown that there are many adverse consequences of early termination of education across the entire life course of an individual. ${ }^{24}$ There are also societal consequences, such as less training of the workforce, less capacity for full functioning in civic life, and greater demand on social welfare entitlements. These results have important implications for policy debate on how much healthcare a society should provide to its citizens in order to reduce these negative consequences. Although cultural values about the importance of mental health relative to competing social issues are likely to vary widely across countries, our findings suggest that few countries, whether they be highincome or LAMI, can afford to forgo the opportunity to develop early interventions and treatments for mental disorders in order to minimise their costly burden for society and vulnerable citizens. A focus on termination of education may also bring to the attention of education departments and school administrators the importance of tackling problems such as substance use and impulse control disorders with mental health interventions. This is especially salient in LAMI countries where suicide and psychiatric diseases are highly stigmatised and priority for mental health research and programmes is low. ${ }^{27}$

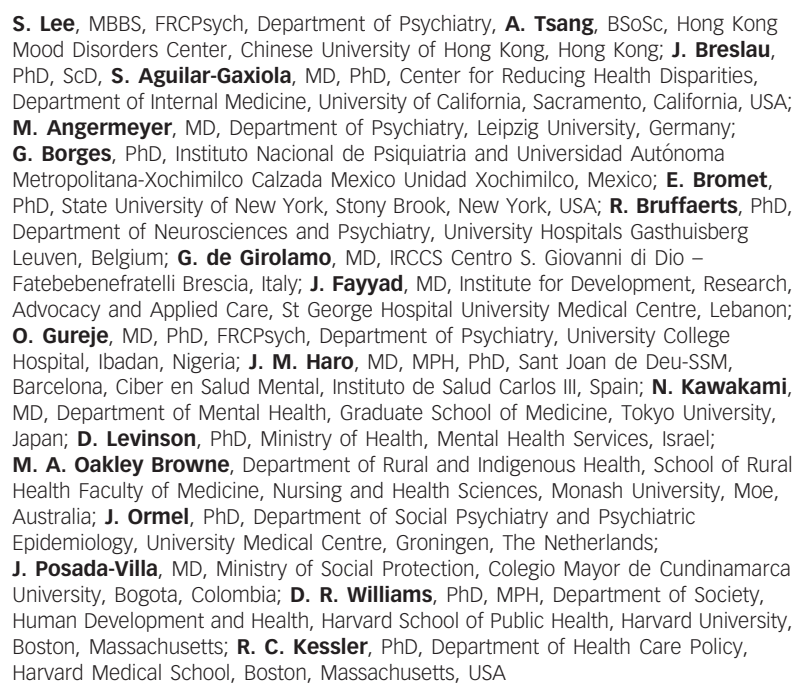

S. Lee, MBBS, FRCPsych, Department of Psychiatry, A. Tsang, BSoSc, Hong Kong Mood Disorders Center, Chinese University of Hong Kong, Hong Kong; J. Breslau, $\mathrm{PhD}, \mathrm{SCD}, \mathbf{S}$. Aguilar-Gaxiola, MD, PhD, Center for Reducing Health Disparities, Department of Internal Medicine, University of California, Sacramento, California, USA; M. Angermeyer, MD, Department of Psychiatry, Leipzig University, Germany; G. Borges, PhD, Instituto Nacional de Psiquiatria and Universidad Autónoma Metropolitana-Xochimilco Calzada Mexico Unidad Xochimilco, Mexico; E. Bromet, PhD, State University of New York, Stony Brook, New York, USA; R. Bruffaerts, PhD, Department of Neurosciences and Psychiatry, University Hospitals Gasthuisberg Leuven, Belgium; G. de Girolamo, MD, IRCCS Centro S. Giovanni di Dio Fatebebenefratelli Brescia, Italy; J. Fayyad, MD, Institute for Development, Research, Advocacy and Applied Care, St George Hospital University Medical Centre, Lebanon; o. Gureje, MD, PhD, FRCPsych, Department of Psychiatry, University College Hospital, Ibadan, Nigeria; J. M. Haro, MD, MPH, PhD, Sant Joan de Deu-SSM, Barcelona, Ciber en Salud Mental, Instituto de Salud Carlos III, Spain; N. Kawakami, MD, Department of Mental Health, Graduate School of Medicine, Tokyo University, Japan; D. Levinson, PhD, Ministry of Health, Mental Health Services, Israel; M. A. Oakley Browne, Department of Rural and Indigenous Health, School of Rural Health Faculty of Medicine, Nursing and Health Sciences, Monash University, Moe, Australia; J. Ormel, PhD, Department of Social Psychiatry and Psychiatric Epidemiology, University Medical Centre, Groningen, The Netherlands;

J. Posada-Villa, MD, Ministry of Social Protection, Colegio Mayor de Cundinamarca University, Bogota, Colombia; D. R. Williams, PhD, MPH, Department of Society, Human Development and Health, Harvard School of Public Health, Harvard University, Boston, Massachusetts; R. C. Kessler, PhD, Department of Health Care Policy, Harvard Medical School, Boston, Massachusetts, USA

Correspondence: Professor Sing Lee, Director, Hong Kong Mood Disorders Centre, 7A, Block E, Staff Quarters, Prince of Wales Hospital, Shatin, NT, Hong Kong. Email: singlee@cuhk.edu.hk

First received 13 May 2008, final revision 21 Aug 2008, accepted 11 Nov 2008

\section{Funding}

These activities were supported by the US National Institute of Mental Health (R01MH070884), the John D. and Catherine T. MacArthur Foundation, the Pfizer Foundation, the US Public Health Service (R13-MH066849, R01-MH069864, and R01-DA016558), the Fogarty International Center (FIRCA R01-TW006481), the Pan American Health Organization, Eli Lilly \& Co, Ortho-McNeil Pharmaceutical, Inc, GlaxoSmithKline and Bristol-Myers Squibb. The Chinese World Mental Health Survey Initiative is supported by the Pfizer Foundation. The Colombian National Study of Mental Health is supported by the Ministry of Social Protection. The European Study of the Epidemiology of Mental Disorders (ESEMeD) is funded by the European Commission (contracts QLG5-1999-01042; SANCO 2004123), the Piedmont Region (Italy). Fondo de Investigación Sanitaria, Instituto de Salud Carlos III, Spain (FIS 00/ 0028), Ministerio de Ciencia y Tecnología, Spain (SAF 2000-158-CE), Departament de Salut, Generalitat de Catalunya, Spain, Instituto de Salud Carlos III (CIBER CB06/02/0046, RETICS RD06/0011 REM-TAP) and other local agencies and by an unrestricted educational grant from GlaxoSmithKline. The Israel National Health Survey is funded by the Ministry of Health with support from the Israel National Institute for Health Policy and Health Services Research and the National Insurance Institute of Israel. The World Mental Health Japan Survey is supported by the Grant for Research on Psychiatric and Neurological Diseases and Mental Health (H13-SHOGAl-023, H14-TOKUBETSU-026, H16-KOKORO-013) from the Japan Ministry of Health, Labour and Welfare. The Lebanese National Mental Health Survey (LEBANON) is supported by the Lebanese Ministry of Public Health, the WHO (Lebanon), Act 4 Lebanon, anonymous private donations to IDRAAC, Lebanon, and unrestricted grants from Janssen Cilag, Eli Lilly, GlaxoSmithKline, Roche and Novartis. The Mexican National Comorbidity Survey (MNCS) is supported by the National Institute of Psychiatry Ramon de la Fuente (INPRFMDIES 4280) and by the National Council on Science and Technology (CONACYT-G30544-H), with supplemental support from the Pan American Health Organization. Te Rau Hinengaro: The New Zealand Mental Health Survey (NZMHS) is supported by the New Zealand Ministry of Health, Alcohol Advisory Council and the Health Research Council. The Nigerian Survey of Mental Health and Wellbeing (NSMHW) is supported by the WHO (Geneva), the WHO (Nigeria) and the Federal Ministry of Health, Abuja, Nigeria. The South Africa Stress and Health Study (SASH) is supported by the US National Institute of Mental Health (R01-MH059575) and National Institute of Drug Abuse with supplemental funding from the South African Department of Health and the University of Michigan. The Ukraine Comorbid Mental Disorders during Periods of Social Disruption (CMDPSD) study is funded by the US National Institute of Mental Health (RO1-MH61905). The US National Comorbidity Survey Replication (NCS-R) is supported by the National Institute of Mental 
Health (U01-MH60220) with supplemental support from the National Institute of Drug Abuse, the Substance Abuse and Mental Health Services Administration, the Robert Wood Johnson Foundation (grant 044708) and the John W. Alden Trust.

\section{Acknowledgements}

The surveys discussed above were carried out in conjunction with the World Health Organization World Mental Health (WMH) Survey Initiative. We thank the WMH staff fo assistance with instrumentation, fieldwork and data analysis.

\section{References}

1 Buchmann C, Hannum E. Education and stratification in developing countries: a review of theories and research. Annu Rev Sociol 2001; 27: 77-102.

2 Kessler RC, Foster CL, Saunders WB, Stang PE. Social consequences of psychiatric disorders, I. Educational attainment. Am J Psychiatry 1995; 152: 1026-32.

3 Johnson JG, Cohen P, Dohrenwend BP, Link BG, Brook JS. A longitudinal investigation of social causation and social selection processes involved in the association between socioeconomic status and psychiatric disorders. J Abnorm Psychol 1999; 108: 490-9.

4 Miech RA, Caspi A, Moffitt TE, Wright BE, Silva PA. Low socioeconomic status and mental disorders: a longitudinal study of selection and causation during young adulthood. Am J Sociology 1999; 104: 1096-131.

5 Woodward LJ, Fergusson DM. Life course outcomes of young people with anxiety disorders in adolescence. J Am Acad Child Adol Psychiatry 2001; 40 1086-93.

6 Fergusson, DM, Woodward L. Mental health, educational, and social role outcomes of adolescents with depression. Arch Gen Psychiatry 2001; 59: 225-31

7 Ormel J, Petukhova M, Chatterji S, Aguilar-Gaxiola S, Alonso J, Angermeyer $\mathrm{MC}$, et al. Disability and treatment of specific mental and physical disorders across the world. Br J Psychiatry 2008; 192: 368-75.

8 De Graaf R, Kessler RC, Fayyad J, ten Have M, Alonso J, Angermeyer M, et al. The prevalence and effects of adult attention-deficit/hyperactivity disorder (ADHD) on the performance of workers: results from the WHO World Mental Health Survey Initiative. Occup Environ Med 2008; 65: 835-42.

9 Kessler RC, Ustun TB. The World Mental Health (WMH) Survey Initiative Version of the World Health Organization (WHO) Composite International Diagnostic Interview (CIDI). Int J Methods Psych Res 2004; 13: 93-121.

10 United Nations Development Program. Human Development Report 2004 Cultural Liberty in Today's Diverse World. United Nations, 2004 (http:// hdr.undp.org/en/media/hdr04_complete.pdf).

11 Alonso J, Angermeyer MC, Lepine JP. The European Study of the Epidemiology of Mental Disorders (ESEMeD) project: an epidemiological basis for informing mental health policies in Europe. Acta Psychiatr Scand 2004; 109: $5-7$.

12 American Psychiatric Association. Diagnostic and Statistical Manual of Mental Disorders (4th edn) (DSM-IV). APA, 1994.

13 Kessler RC, Davis CG, Kendler KS. Childhood adversity and adult psychiatric disorder in the US National Comorbidity Survey. Psychol Med 1997: 27: 1101-19.

14 Thornberry TP, Ireland TO, Smith CA. The importance of timing: the varying impact of childhood and adolescent maltreatment on multiple problem outcomes. Dev Psychopathol 2001; 13. 957-79.
15 Kessler RC, Haro JM, Heeringa SG, Pennell BE, Ustun TB. The World Health Organization World Mental Health Survey Initiative. Epidemiol Psichiatr Soc 2006; 15: 161-6.

16 Kalbfleisch JD, Prentice RL. The Statistical Analysis of Failure Time Data. Wiley, 1980.

17 Efron B. Logistic regression, survival analysis, and the Kaplan-Meier curve. J Am Stat AsSOC 1988; 83: 414-25

18 Willett JB, Singer JD. Investigating onset, cessation, relapse and recovery: why you should, and how you can, use discrete-time survival analysis to examine event occurrence. J Consult Clin Psychol 1993; 61: 952-65.

19 Mare RD. Social background and school continuation decisions. J Am Stat Assoc 1980; 75: 295-305.

20 Mare RD. Change and stability in educational stratification. Am Sociol Rev 1981; 46: 72-87.

21 Sewell WH, Hauser RM. Causes and consequences of higher education: models of the status attainment process. In Schooling and Achievement in American Society (eds WH Sewell, RM Hauser \& DL Featherman). Academic Press, 1976.

22 Kessler RC, Berglund PA, Demler O, Jin R, Walters EE. Lifetime prevalence and age-of-onset distributions of DSM-IV disorders in the National Comorbidity Survey Replication (NCS-R). Arch Gen Psychiatry 2005; 62 593-602.

23 Featherman DL. Schooling and occupational careers: constancy and change in worldly success. In Constancy and Change in Human Development (eds OG Brim \& J Kagan). Harvard University Press, 1980.

24 Koivusilta LK, Rimpela AH, Rimpela M, Vikat A. Health behavior-based selection into educational tracks starts in early adolescence. Health Educ Res 2001; 16: 201-14

25 Eaton WW, Anthony JC, Tepper S, Dryman A. Psychopathology and attrition in the Epidemiological Catchment Area Study. Am J Epidemiol 1992; 135: 1051-9.

26 Shen YC, Zhang MY, Huang YQ, He YL, Liu ZR, Cheng H, et al. Twelve-month prevalence, severity, and unmet need for treatment of mental disorders in metropolitan China. Psychol Med 2006; 36: 257-67.

27 Jorm AF, Wright A. National surveys of mental disorders: are they researching scientific facts or constructing scientific facts? Aust $N \mathrm{Z}$ Psychiatry 2007; 40: 830-4.

28 Weich S, Araya R. International and regional variation in the prevalence of common mental disorders: do we need more surveys? Br J Psychiatry 2004 184: 289-90.

29 Bennett KJ, Brown KS, Boyle MR, Yvonne OD. Does low reading achievement at school entry cause conduct problems? Soc Sci Med 2003; 56: 2443-8.

30 Overbeek G, Biesecker G, Kerr M, Stattin H, Meeus W, Engels RCME. Co-occurrence of depressive moods and delinquency in early adolescence: the role of failure expectations, manipulativeness, and social contexts. Int J Behav Dev 2006; 30: 433-43.

31 Hishinuma ES, Else IRN, Chang JY, Goebert DA, Nishimura ST, Choi-Misailidis $\mathrm{S}$, et al. Substance use as a robust correlate of school outcome measures for ethnically diverse adolescents of Asian/Pacific Islander ancestry. Sch Psychol Q 2006; 21: 286-322.

32 Tarumi S, Ichimiya A, Yamada S, Umesue M, Kuroki T. Taijin Kyofusho in university students: patterns of fear and predispositions to the offensive variant. Transcult Psychiatry 2004; 41: 533-46.

33 Wang PS, Angermeyer M, Borges G, Bruffaerts R, Chiu WT, de Girolamo G, et al. Delay and failure in treatment seeking after first onset of mental disorders in the WHO World Mental Health (WMH) Survey Initiative. World Psychiatry 2007; 6: 177-85. 